\title{
Maria Teresa Lopes Pereira, Os Cavaleiros de Santiago em Alcácer do Sal. Século XII a fins do século XV
}

\author{
Isabel Cristina Fernandes
}

\section{(2) OpenEdition \\ Journals}

Edição electrónica

URL: http://journals.openedition.org/medievalista/1294

DOI: 10.4000/medievalista.1294

ISSN: 1646-740X

Editora

Instituto de Estudos Medievais - FCSH-UNL

\section{Refêrencia eletrónica}

Isabel Cristina Fernandes, « Maria Teresa Lopes Pereira, Os Cavaleiros de Santiago em Alcácer do Sal. Século XII a fins do século XV », Medievalista [Online], 21 | 2017, posto online no dia 01 junho 2017, consultado o 23 setembro 2020. URL : http://journals.openedition.org/medievalista/1294 ; DOI : https://doi.org/10.4000/medievalista.1294

\section{(c) (7) 8}

Mediavalista está licenciado com uma Licença Creative Commons - Atribuição-NãoComercial 4.0 Internacional. 
Título / Title: Recensão: PEREIRA, Maria Teresa Lopes - Os Cavaleiros de Santiago em Alcácer do Sal. Século XII a fins do século XV. Lisboa: Edições Colibri, 2015 (386 pp.) Autor(es) / Author(s): Isabel Cristina Fernandes Universidade / University: Universidade de Évora Faculdade e Departamento / Unidade de Investigação - Faculty and Department / Research Center: CIDEHUS - Centro Interdisciplinar de História, Culturas e Sociedades / GEsOS - Gabinete de Estudos sobre a Ordem de Santiago Código Postal / Postcode: 2954-001

Cidade / City: Palmela

País / Country: Portugal

Email Institucional / Institutional email: isacrisff@gmail.com

Fonte: Medievalista [Em linha]. Direc. Bernardo Vasconcelos e Sousa. Lisboa: IEM. Disponível em:

http://www2.fcsh.unl.pt/iem/medievalista/MEDIEVALISTA21/fernandes2109.html ISSN: 1646-740X

Data de recepção do texto / Received for publication: 26 de Julho de 2016 


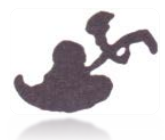

\section{Recensão / Review: PEREIRA, Maria Teresa Lopes - Os Cavaleiros de Santiago em Alcácer do Sal. Século XII a fins do século XV. Lisboa: Edições Colibri, 2015 (386 pp.)}

\author{
Isabel Cristina Fernandes
}

Quando o professor José Mattoso, no prefácio deste livro, nos fala da "busca do tesouro” como uma inquietação do homem que não se resigna à sua finitude e o impele a seguir em frente, a criar, a contemplar, a descobrir, está-nos a aproximar da autora deste livro e dos seus propósitos. São propósitos de um “peregrinar” de vocação científica mas também envolto em antigas e profundas emoções que ligam Maria Teresa Lopes Pereira a esta vila de Alcácer do Sal e à Ordem de Santiago. José Mattoso revelanos essa duplicidade de objectivos na investigação e na produção escrita da autora, sublinhando que esses aspetos em nada afectam o valor científico da obra (que reputa de rigorosa e metodologicamente intocável), antes pelo contrário, dotam-na de uma tonalidade quente e apaixonada que favorece o leitor, seja ele o historiador ou o cidadão comum interessado no conhecimento do passado da sua terra ou do seu país.

Esta obra segue um percurso cronológico que se inicia em 1158, data da primeira conquista portuguesa de Alcácer, e termina sensivelmente em finais do século XV. Para o primeiro período da história medieval cristã do castelo e da vila, entre 1158 e 1217, a autora fornece-nos uma síntese bastante completa e recheada de pequenos novos contributos respigados das fontes, permitindo-nos a percepção de uma Alcácer historicamente pouco trabalhada. A partir do poema "Carmen", escrito pelo cruzado Gosuíno, a autora elabora uma excelente descrição do cerco e da batalha campal de 1217, entre as hostes almóadas e cristãs, e marcante não só para Alcácer, como para os destinos do jovem reino português. Recupera, na sua abordagem, a anterior análise do Gosuini de expugnatione Salaciae carmen, publicada em 1996, completando-a com elementos entretanto coligidos.

Medievalista online $\mathrm{N}^{\circ} 21$ | Janeiro - Junho 2017 @ IEM - Instituto de Estudos Medievais 2 www2.fcsh.unl.pt/iem/medievalista 
Este episódio bélico é o mote para se lançar na análise dos principais períodos de instalação da sede da Ordem de Santiago na povoação, entre 1218 e 1245 e, depois da passagem por Mértola, entre 1303 e 1482. Através dessa análise, cheia de novidade, podemos entrever o panorama político em que orbitava o ramo português da Ordem de Santiago e as diligências desenvolvidas com o intuito de conseguir a independência de Uclés.

Particularmente interessante é a abordagem da autora ao castelo medieval cristão de Alcácer, entre os séculos XIII e XIV. Para além de compilar os dados de outros estudiosos, sem esquecer a componente arqueológica, avança com detalhes colhidos em fontes diversas, sobretudo do século XIV, e que lhe permitem desenhar um novo olhar sobre a cerca muralhada e as torres da fortaleza, desde a sua função como quartel militar e sede religiosa à relação com a vila e o porto e ao seu papel na estruturação do povoamento. Aos edifícios intra-muros é dedicada especial atenção: os paços do mestre, o convento medievo, a capela de Santiago. Para além dos aspectos materiais, construtivos e de organização espacial, são-nos fornecidos elementos para a compreensão da vida da comunidade dos freires, nas suas dimensões militar, espiritual e administrativa, desde a tomada do hábito à profissão, incluindo as várias vertentes da aplicação prática da normativa da Ordem.

No capítulo da religiosidade aborda também a questão da devoção da Ordem ao apóstolo Santiago e elenca os dados que identificam Alcácer do Sal como um dos pontos importantes do Caminho peregrinacional a Santiago de Compostela.

Segue-se a análise da emblemática igreja duodecentista de Santa Maria do Mártires, localizada fora de portas e que foi panteão de mestres da Ordem de Santiago. Monumento icónico para os santiaguistas, é-o também pela singularidade arquitectónica da capela-panteão, de planta centrada octogonal, dita a Capela dos Mestres (1333). O conjunto é revisitado por Maria Teresa Lopes Pereira, que retoma e enobrece anteriores textos seus, proporcionando-nos uma visão global do edificado, dos sepultamentos dos líderes santiaguistas e a sua leitura histórico-artística de algumas peças escultóricas, com destaque para a célebre imagem de Nossa Senhora da Cinta, em cuja análise se demora com evidente deleite. 
O quarto grande apartado desta obra centra-se no governo da Ordem de Santiago:

- os Capítulos Gerais, ou seja, as reuniões restritas do mestre com as dignidades de maior vulto na Ordem, onde se tomavam as decisões fundamentais para a vida da milícia, são tratados com algum detalhe, apresentando-se um quadro que sistematiza os capítulos realizados entre 1291 e 1492;

- a listagem dos mestres e administradores da Ordem de Santiago entre 1290 e 1492, ou seja, de D. João Fernandes ao príncipe D. João (futuro D. João II). Para cada um deles é sistematizada informação biográfica, de actos administativos sob a sua alçada e de acontecimentos que contextualizam os seus governos. Apesar de outros historiadores se terem debruçado antes sobre estes mestres, não existia de facto uma compilação para este espectro cronológico, com informação actualizada de várias fontes e bibliografia, enriquecida com observações e interpretações da autora e aproximações à realidade de Alcácer.

Ao último personagem, o príncipe D. João e, depois, ao monarca, Maria Teresa Lopes Pereira dedica especial atenção, confessando o seu denodado interesse por esta figura, ao estudo da qual consagra, desde há muito, parte das suas pesquisas. Com recurso a fontes cronísticas, à chancelaria de $\mathrm{D}$. Afonso $\mathrm{V}$ e à consulta de estudos de outros autores, traça-nos o percurso biográfico de D. João até assumir o trono, para depois se concentrar nos aspetos da sua governação da Ordem de Santiago. É sobretudo nesta abordagem que a autora nos concede nova e ampla informação, a partir de documentação da Ordem de Santiago conservada na Torre do Tombo, em boa parte inédita. Estamos perante a mobilização de um manancial de dados que representa um óptimo contributo para o estudo desta Ordem no século XV, com novidades para o período de transição da sede de Alcácer para Palmela, para a acção reformista do monarca enquanto administrador de Santiago e Avis, até à entrega do mestrado a D. Jorge.

No capítulo quinto e último, Maria Teresa Lopes Pereira remata este seu estudo com um breve olhar sobre o declínio dos paços do mestre e do convento de Alcácer, em inícios de quinhentos, para depois nos introduzir na nova era do amuralhado alcaçarino: a da construção do Convento de Clarissas, inaugurado em 1573. Adianta ainda alguma informação sobre a gestão e a ocupação da fortaleza desde o séc. XVIII à actualidade. 
A riqueza informativa e o valor científico da obra fortalecem-se pelas pertinentes notas de rodapé, pela completa bibliografia e pela referência das fontes consultadas, pela inclusão de um índice remissivo, mas também e sobretudo pelos anexos documentais. Trata-se de um conjunto de transcrições e um índice documental que nobilitam a obra e a consagram como um importante recurso de investigação. Estes anexos incluem: a transcrição e tradução para português da Memória Cruzadística sobre a Tomada da Vila de Alcácer (1217); a transcrição de uma contenda entre a Ordem de Santiago e o concelho de Alcácer (1349); a transcrição de um conjunto de documentos relativos a propriedades da Ordem de Santiago na vila e no termo de Alcácer, do terceiro quartel do século XV: oito cartas de emprazamento; três contratos de renovação de emprazamentos; cinco cartas de aforamento; um tombo de aforamentos e emprazamentos; uma sentença da Ordem de Santiago sobre delimitação de termos; a transcrição do Regimento dos Visitadores do Mestrado de Santiago, de 1478; a transcrição de um relatório e determinações de visitação a Alcácer, de 1480. E, por fim, uma listagem, sistematizada num extenso quadro, onde se descreve o conteúdo de um conjunto de diplomas do príncipe D. João, balizados entre 1476-1479, desde cartas de mercê, de tença, ementas de cartas a confirmações e nomeações. A importância desta listagem de diplomas não se circunscreve a Alcácer do Sal, alarga-se a outras cidades e regiões, como Santarém, Lisboa, Palmela, Setúbal, Estremoz, Avis, Évora, Beja, entre outras, tornando-se matéria de interesse para outras pesquisas.

De facto, Maria Teresa Lopes Pereira coloca à disposição dos investigadores de história medieval e das Ordens Militares mais um valioso livro que, como ela própria afirma na introdução, é fruto de muito labor, de muita persistência e de reflexões que foram sendo maturadas ao longo dos anos. Quando lemos o que escreveu, reconstituimos mentalmente, com facilidade, o quotidiano da Alcácer medieval, do seu convento espatário, do seu castelo, imagens proporcionadas pela clareza e pelo pormenor do discurso mas que são também resultado de muitas horas de consultas bibliográficas, de trabalho de arquivo, de questionamento das fontes, de produção de escrita. 


\section{COMO CITAR ESTE ARTIGO}

\section{Referência electrónica:}

FERNANDES, Isabel Cristina - "Recensão: PEREIRA, Maria Teresa Lopes - Os

Cavaleiros de Santiago em Alcácer do Sal. Século XII a fins do século XV. Lisboa:

Edições Colibri, 2015 (386 pp.)”. Medievalista 21 (Janeiro-Junho 2017). [Em linha] [Consultado dd.mm.aaaa]. Disponível em

http://www2.fcsh.unl.pt/iem/medievalista/MEDIEVALISTA21/fernandes2109.html ISSN 1646-740X.

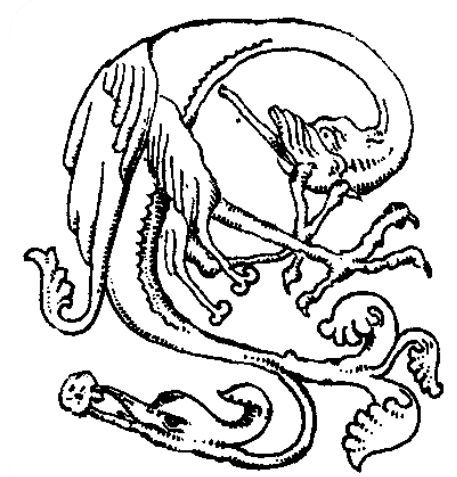

